\title{
Dynamics of larval patches: spatial distribution of fiddler crab larvae in Delaware Bay and adjacent waters
}

\author{
Christopher Petrone ${ }^{1}$, Lauren B. Jancaitis ${ }^{1}$, M. Brandon Jones ${ }^{1}$, \\ Cecily C. Natunewicz ${ }^{2}$, Charles E. Tilburg ${ }^{1,3}$, Charles E. Epifanio ${ }^{1, *}$ \\ ${ }^{1}$ Graduate College of Marine Studies, University of Delaware, Lewes, Delaware 19958, USA \\ ${ }^{2}$ United States Naval Academy, Annapolis, Maryland 21402, USA \\ ${ }^{3}$ Present address: Department of Marine Sciences, University of Georgia, Athens, Georgia 30602, USA
}

\begin{abstract}
In this paper, we present results of a 4 year investigation of the dynamics of patches of fiddler crab larvae (Uca spp.) in southern Delaware Bay and the nearby coastal ocean. The study addressed 4 research questions: (1) What are the processes that result in the genesis and transport of patches; (2) How large are patches; (3) What is the density of larvae within a typical patch; and (4) How long do patches remain integral? The investigation included characterization of the 2-dimensional distribution of larvae as determined by high-frequency plankton sampling and determination of trajectories of patches using satellite technology. We also conducted numerical model simulations of the early stages of patch formation and compared model outcomes to real world observations. Results of earlier investigations have shown that fiddler crab larvae are released near the time of high tide during nocturnal spring tidal periods. Our results indicate that newly hatched fiddler crab larvae are exported from small tidal rivers in a single, long continuous patch. These patches probably result from synchronized spawning of a large number of females. Along-stream dimensions of the patches at our sampling site were at least 8 to $9 \mathrm{~km}$, and maximum densities of larvae were as high as $3 \times$ $10^{4} \mathrm{~m}^{-3}$. Only part of each patch exited the river during the first ebb tide following hatching. Numerical simulations showed that the remaining portion exited the river during subsequent ebb tides following hatching. Patches observed in Delaware Bay were no longer constrained by the river banks and consequently spread out in response to dissipative physical processes; maximum densities were $\sim 10^{3} \mathrm{~m}^{-3}$. Numerical simulations demonstrated a similar change in shape of patches as they entered the bay. Trajectories of bay patches were strongly influenced by tidal circulation, which resulted in transport of larvae back and forth along the shore of the bay at tidal frequency. Patches of Uca larvae were also observed on the inner shelf near the mouth of the bay. Shelf patches consisted mainly of advanced-stage zoea larvae, with maximum densities up to several hundred $\mathrm{m}^{-3}$. Megalopae were also observed in patch-like aggregations, both in open bay water and in the river; densities were on the order of $10^{2} \mathrm{~m}^{-3}$.
\end{abstract}

KEY WORDS: Uca larvae $\cdot$ Zoeae $\cdot$ Megalopae $\cdot$ Patches $\cdot$ Models Resale or republication not permitted without written consent of the publisher

\section{INTRODUCTION}

Larval forms of some fish and invertebrates occur in spatially discrete patches (Epifanio 1988, 1995, Jones \& Epifanio 1995, Epifanio \& Garvine 2001). These patches may be formed by a variety of physical and biological processes (Ouellet \& Lefaivre 1994, Ashjian et al. 1994, Franks 1997) and are thought to benefit larvae in several ways, including more efficient interaction with prey organisms (MacKenzie 2000) and protection from planktonic predators (Natunewicz 2001). Nevertheless, there have been few studies that docu- 
ment the spatial scale of larval patches (Williams \& English 1992, Stabeno et al. 1996, Lamare \& Stewart 1998) and even fewer that have examined how patches are maintained or dispersed (Fortier \& Leggett 1984). Perhaps the most comprehensive study of invertebrate larval patch dynamics is a recent investigation of the blue crab Callinectes sapidus in the Middle Atlantic Bight along the east coast of North America. That study has provided a detailed picture of the spatial scale of patches of zoea larvae and has utilized satellite technology to tag representative patches and follow their trajectories for periods of up to $1 \mathrm{wk}$ (Natunewicz \& Epifanio 2001, Natunewicz et al. 2001). Because the exact times and locations of blue crab spawning are not well known (Tankersley et al. 1998), that investigation did not address the actual formation of patches. Thus, the age of the patches in the study and the processes important in their genesis remain uncertain.

In contrast to blue crabs, the spawning biology of fiddler crabs (genus: Uca) has been well documented and provides a convenient vehicle for investigating the early stages of patch formation. Two species of fiddler crab (U. pugnax and $U$. minax) are common in salt marshes fringing estuaries like Delaware Bay in the southern Middle Atlantic Bight. In this region, fiddler crabs spawn throughout the summer months with peak hatching in July and August (Dittel \& Epifanio 1982, Lambert \& Epifanio 1982, Brookins \& Epifanio 1985). Hatching occurs at night during spring-tide periods near the time of high slack water (Wheeler 1978, Christy 1982, Christy \& Morgan 1998). Larvae from populations near the mouth of Delaware Bay are flushed out of marsh creeks on the ensuing ebb tide to the open waters of the primary estuary-and eventually to the adjacent coastal ocean where they pass through 5 zoeal stages (Z-I to V) before molting to the megalopa stage. Megalopae are transported back to the bay via the gravitational circulation of the estuary (Epifanio et al. 1988). Once back in the estuary, megalopae begin a pattern of swimming behavior that results in migration to surface waters during nocturnal flooding tides and bottom waters during ebb tides and diel flood tides (Tankersley \& Forward 1994). This migration allows the megalopae to utilize vertical shear in tidal currents for eventual transport to juvenile settlement sites within the marshes.

In this paper, we present results of a 4 yr investigation of the dynamics of patches of fiddler crab larvae in southern Delaware Bay and the nearby coastal ocean. The study addressed 4 research questions: (1) What are the processes that result in the genesis and transport of patches; (2) How large are patches; (3) What is the density of larvae within a typical patch; and (4) How long do patches remain integral? The investigation included characterization of the 2-dimensional distribution of larvae as determined by high frequency plankton sampling and determination of trajectories of patches using satellite technology. To address the question of patch genesis more fully, we also conducted numerical model simulations of the early stages of patch formation and compared model outcomes to real world observations.

\section{MATERIALS AND METHODS}

Study site. The investigation was conducted over a 4 year period (1999 to 2002) in southern Delaware Bay and the adjacent coastal ocean (Fig. 1). Specific collections were made in the Broadkill River (designated by arrow in Fig. 1), in open water of the bay (area shown as $\mathrm{A}$ in Fig. 1), and in waters of the inner continental shelf near the mouth of the bay (area shown as B in Fig. 1). The Broadkill River is a shallow secondary estuary (average depth $\sim 3 \mathrm{~m}$ at low tide) that drains extensive areas of salt marsh before flowing into the main body of Delaware Bay through Roosevelt Inlet. The width of the river rarely exceeds $100 \mathrm{~m}$ over its entire course; width at the sampling site was $\sim 60 \mathrm{~m}$. During summer, the lower Broadkill is a well-mixed estuary that experiences semidiurnal tides with a mean vertical tide range of $1.2 \mathrm{~m}$ (Dewitt \& Daiber 1973). Directly south of the Broadkill River, and also emptying through Roosevelt Inlet, is the deeper $(\sim 5 \mathrm{~m})$ Lewes-Rehoboth Canal. Delaware Bay itself is a partially mixed estuary that showed weak stratification during the summer months when the study was conducted (Garvine 1991, Wong \& Münchow 1995). Buoyancy-driven flow exits the bay along the southern shore and continues southward along the inner continental shelf as the Delaware Coastal Current (Münchow \& Garvine 1993). The coastal current interacts with a wind-driven cycle of upwelling and downwelling to provide the main agents controlling transport of surface-dwelling larval forms in the region (Epifanio 1995, Epifanio \& Garvine 2001, Natunewicz et al. 2001).

General aspects of sampling. Samples were collected from surface waters with $0.5 \mathrm{~m}$ plankton nets (253 $\mu \mathrm{m}$ mesh) fitted with flow meters in the mouth of the net (General Oceanics Model 2030). Preserved samples were split with a Folsom plankton splitter (Dittel \& Epifanio 1982). The number of splits was determined by the size of the sample. Sub-samples were chosen randomly for further analysis. Larvae in each sub-sample were enumerated and identified through standard microscopy, and densities were calculated using relevant flow meter readings. We did not distinguish between the 2 likely species of $U C a$ ( $U$. pugnax and $U$. minax) because examination of mor- 


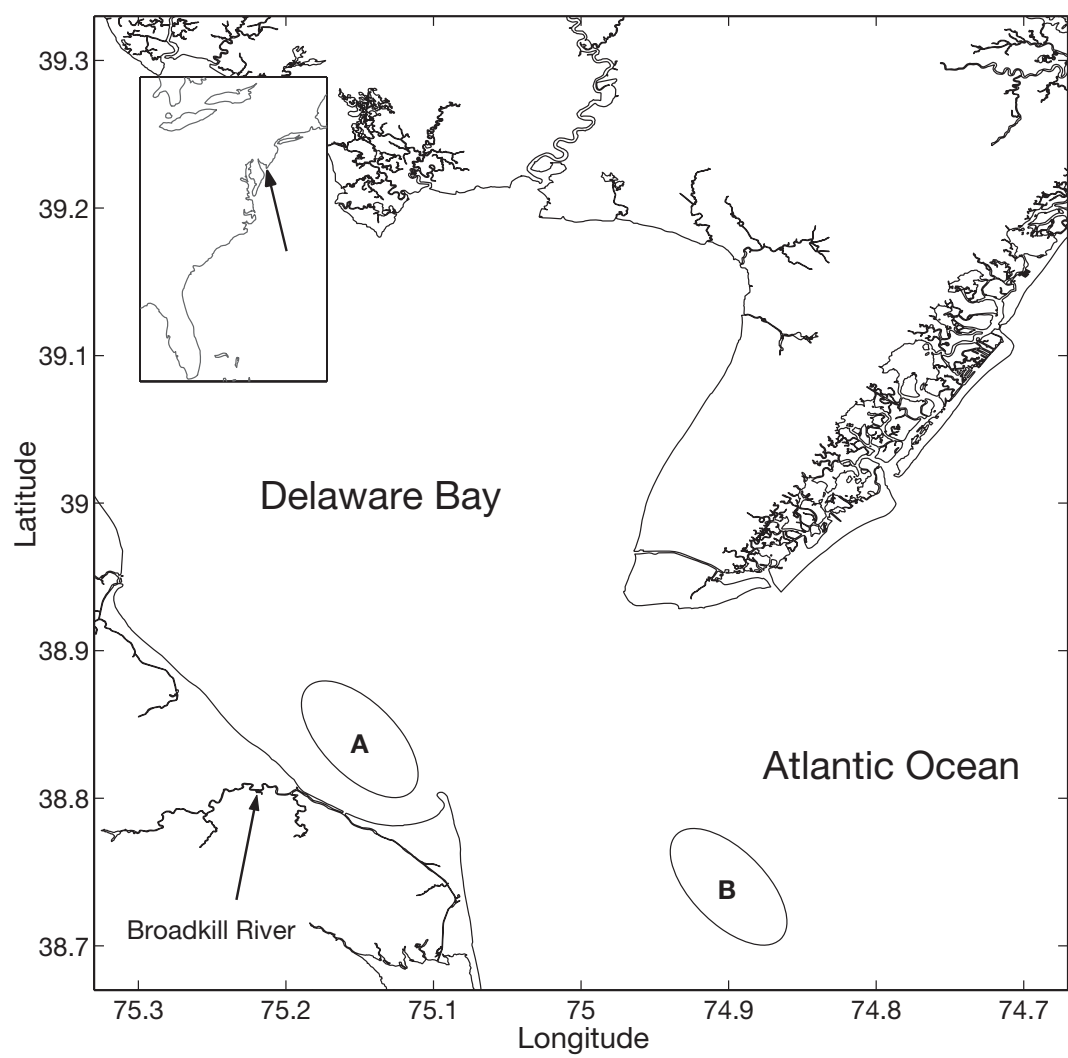

Fig. 1. Map of study site in the mouth of Delaware Bay and in the adjacent coastal ocean. Inset shows location in southern Middle Atlantic Bight along the east coast of North America. A = general location of plankton sampling in Delaware Bay. B = general location of sampling in coastal ocean. Arrow shows general location of Broadkill River. Sampling station was located $\sim 500 \mathrm{~m}$ upstream of the mouth

phological characteristics does not allow identification of fiddler crab larvae beyond the level of genus (Sandifer 1972, O'Connor 1990).

Genesis of patches. This part of the study concerned the export of newly hatched zoeae (Z-I) from salt marsh spawning areas drained by the Broadkill River (Fig. 1). Although both the Lewes-Rehoboth Canal and the Broadkill River empty into Delaware Bay through Roosevelt Inlet, within this study we focused on the Broadkill River. The canal provides a source of water during ebb tide that tends to dilute the concentrations of larvae entering Delaware Bay from the Broadkill River. However, our sampling station in the Broadkill was located $500 \mathrm{~m}$ upstream from the inlet and plankton samples taken at the station were not influenced by outflow from the canal. This investigation had an Eulerian character in that it relied on high frequency sampling of a water mass as it was advected past a fixed station by ebb tidal currents. The sampling station was located about $500 \mathrm{~m}$ upstream from the mouth of the river at approximately $38.8^{\circ} \mathrm{N}, 75.2^{\circ} \mathrm{W}$. Sampling of newly hatched zoea larvae (Z-I) was con- ducted during nocturnal spring tides in June and August 2001. Each sampling effort consisted of nearly continuous plankton collections over a $7 \mathrm{~h}$ period that began at high slack water and encompassed the entire ebb phase of the tide. We did not sample during the subsequent flood phase because we had assumed that newly hatched larvae would exit the river in a single ebb phase (but see results below). Plankton nets were deployed in the tidal stream from a davit mounted on a dock, except near slack water when they were towed from a small boat. All deployments were made in near-surface waters. Previous work had shown no difference in vertical distribution of Z-I UCa larvae at this site (Lambert \& Epifanio 1982, Little \& Epifanio 1991). Each sample consisted of a 2 min deployment every $10 \mathrm{~min}$, resulting in 41 collections per sampling period. Volume of water sampled ranged from $\sim 4$ to $25 \mathrm{~m}^{3}$, depending on tidal current speed.

Data from each night of sampling yielded a time series of larval density at $10 \mathrm{~min}$ intervals over a single ebb phase. This required conversion of each time series to its equivalent spatial series (Jones \& Epifanio 2005). We did this by using data from an S-4 current meter that was moored at the station. Because tidal currents are rectilinear at the study site, the direction toward which the current flowed was always the same during the ebb tide phase. Thus, we could treat the current as a scalar quantity and calculate the displacement of water $(\mathrm{m})$ during each sampling interval as the product of the duration of the interval (600 s) and the average current speed $\left(\mathrm{m} \mathrm{s}^{-1}\right)$ during the interval. Maximum amplitude of tidal current was $\sim 80 \mathrm{~cm} \mathrm{~s}^{-1}$. The total displacement of water on any given night was calculated as the sum of the 10 min displacement values determined over the entire sampling period. This value was then used to derive a spatial series of larval density that was based on the original time series.

Patch dynamics in Delaware Bay. The second part of the study was designed to investigate the 2-dimensional structure of patches of Z-I in open waters of Delaware Bay (Fig. 1). The investigation was conducted in the summers of 2001 and 2002. Each sampling effort consisted of tagging and tracking a patch for periods ranging from 6 to $48 \mathrm{~h}$ post-hatching. Because of logistical constraints, none of these efforts 
were conducted simultaneously with the 2001 dock sampling described in the previous section. Thus, the water parcels sampled in the first and second parts of the study were analogous, but not identical.

The 2001 sampling effort occurred during late August and early September and concentrated on spatial characterization of patches of Z-I immediately after export from the river. Protocol in 2001 consisted of releasing drifters (Horizon Marine) in the mouth of the river during a spring tide period at maximum ebb current. The timing of release was chosen to coincide with maximum transport of newly hatched Z-I from nearby marshes drained by the river. The drifters were identical to those used in earlier work that tracked the trajectories of blue crab larvae in the coastal ocean (Natunewicz et al. 2001) and consisted of a cylindrical buoy attached to a drogue deployed at a depth of $1 \mathrm{~m}$. (Depth in the study region ranged from 3 to $7 \mathrm{~m}$.) The buoy extended $30 \mathrm{~cm}$ above the surface and was fitted with a small strobe light for visual location at night. Each drifter had the capability of transmitting radio signals to earth-orbiting satellites in the ARGOS system for calculation of position. The drifters transmitted radio signals every $90 \mathrm{~s}$. Satellites received these signals as they passed over the study site at irregular intervals from 1 to $6 \mathrm{~h}$. The satellites transmitted fixes at these same intervals. All satellite fixes were archived by the ARGOS system and later downloaded for use in re-constructing the cumulative trajectory of each drifter. The radio transmissions also were received with a shipboard radio-direction-finder, which was used to locate the drifters in real time. Intensive plankton sampling was conducted in the vicinity of a drifter each time that drifter was located with the shipboard radio-direction-finder (see below).

Drifters were tracked from the time of deployment until the subsequent low slack water (i.e. $6 \mathrm{~h}$ posthatching) when intensive plankton sampling was undertaken in an area $\left(\sim 3 \mathrm{~km}^{2}\right)$ around the drifter. The size of the sampling area was determined by estimates of patch size as well as drifter slippage. The $30 \mathrm{~cm}$ extension of the buoy above water results in some slippage of the drifter from the tagged water parcels. Previous work with Horizon drifters indicated a typical slippage of less than $1 \mathrm{~cm} \mathrm{~s}^{-1}$, which would result in maximum movement of the drifter relative to the patch of approximately $500 \mathrm{~m}$ per day. The spatial scales of the sampling area (see Fig. 2) were designed to accommodate this movement. Sampling consisted of a continuous series of $300 \mathrm{~m}$ plankton tows (wherein the retrieval of one net coincided with the deployment of another) from an $8 \mathrm{~m}$ vessel along a W-shaped transect centered on the drifter. The length of each plankton tow and the position of the transect were determined with differential GPS. Accordingly, the transect posi-

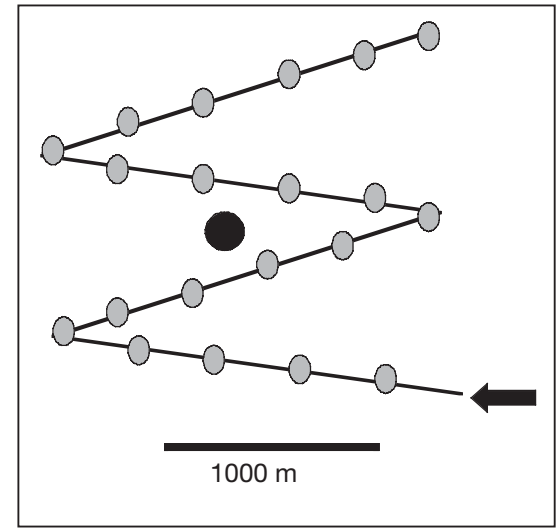

Fig. 2. Conceptual diagram of $\mathrm{W}$-shaped transects used to characterize distribution of Uca zoeae in surface water in Delaware Bay near the mouth of the Broadkill River $\left(\sim 38.8^{\circ} \mathrm{N}\right.$, $75.2^{\circ} \mathrm{W}$; see Fig. 1). Transects were always centered on a satellite-tracked drifter that was attached to a drogue at a depth of $1 \mathrm{~m}$. Sampling consisted of a continuous sequence of $300 \mathrm{~m}$ surface plankton tows over the length of the transect. Black circle indicates location of drifter. Arrow indicates location of deployment of initial plankton net. Gray ovals represent retrieval locations of a given net and deployment of subsequent net. Lines represent trajectory of sampling vessel.

Directional orientation of transect varied with conditions

tion was always fixed relative to the bottom. Thus, plankton sampling was restricted to the period of slack water, which minimized displacement of water relative to the transect.

Sampling in 2002 was conducted in late July and early August and was designed to follow drifters for longer periods of time. Protocol consisted of the deployment of 3 drifters at $300 \mathrm{~m}$ intervals along a $900 \mathrm{~m}$ transect extending southeast from the mouth of the Broadkill (Fig. 1). Drifters were deployed at nocturnal low slack tide, immediately following a presumed Uca spawning event in the marshes drained by the Broadkill. We conducted a $300 \mathrm{~m}$ plankton tow coincident with deployment of each drifter and centered on the location of the drifter. Samples were analyzed immediately to determine the density of Z-I in the vicinity of each drifter; we used these data to choose drifters that were tracked for the duration of each sampling effort. We conducted plankton sampling in the vicinity of these drifters at each succeeding slack water, using methods similar to those employed in 2001.

Larval density fields within the various sampling areas were represented as 2-dimensional maps generated with triangulation-based linear interpolation techniques (Press et al. 1992) that were available as part of the Griddata routine included in Matlab ${ }^{\mathrm{TM}}$ software. Interpolation was done at $200 \mathrm{~m}$ intervals, and we used the Matlab ${ }^{\text {TM }}$ Pcolor routine to represent lar- 
val densities as discrete $200 \mathrm{~m} \times 200 \mathrm{~m}$ squares. While non-linear interpolation techniques (e.g. cubic spline) would have generated smooth contour plots of larval density, we chose a linear approach in order to maximize fidelity to the original data; which we deemed important, given the relatively small number of sampling locations within the respective grids. We also used Matlab ${ }^{\mathrm{TM}}$ software to represent satellite-derived trajectories on relevant map surfaces.

Numerical simulation of patch genesis. In order to supplement the field observations and to examine the dynamics responsible for patch generation, we used a numerical simulation of the region into which we introduced a tracer that corresponded to the observed Uca larvae. We could then compare the observations of the larvae to output from the numerical model, which realistically simulated the physical dynamics within an estuarine environment and allowed for more insight into the effects of different physical dynamics on patch generation. While some larval transport models include vertical swimming, our model assumes a shallow well-mixed water column in which vertical swimming is unlikely to overcome turbulent mixing. The numerical model used for the simulation was ECOM3d, a primitive-equation, finite-difference model (Blumberg \& Mellor 1987). This model has been used extensively to study transport on coastal shelves (e.g. Garvine 1991, Kourafalou et al. 1996). For a complete description of the model, the reader is referred to Kourafalou et al. (1996).

The simulation domain encompassed a portion of the Broadkill River, a portion of the Lewes-Rehoboth Canal, and the mouth of the Delaware Bay (Fig. 3). The only forcing within the model consisted of an oscillating boundary at the coastal ocean (along bay distance $=11 \mathrm{~km}$ ) that drove nearly rectilinear velocities at a semi-diurnal frequency within the bay and the Broadkill River. Comparison of model-generated and observed velocities both in the bay ( 40 to $\left.50 \mathrm{~cm} \mathrm{~s}^{-1}\right)$ and the river ( $\sim 60$ to $80 \mathrm{~cm} \mathrm{~s}^{-1}$ ) revealed good agreement in both magnitude and phase (Bay Velocities: $\mathrm{r}=0.92, \mathrm{p}<0.001$; River Velocities: $\mathrm{r}=0.95, \mathrm{p}<0.001$ ).

In order to reach statistical steady-state, the simulation was run for 14 tidal cycles before the tracer was introduced. The tracer was introduced into the upper meter of the Broadkill River during high slack tide as a single slug with uniform density in both the acrossriver and along-river dimensions. The initial slug extended $7 \mathrm{~km}$ upstream from the mouth of the river. The simulation was then allowed to run for 7 complete tidal cycles $(\sim 3.5 \mathrm{~d})$.

The horizontal grid size for the simulation was $100 \mathrm{~m}$ throughout the domain and the horizontal plane consisted of $225 \times 110$ grid points. The depth was $5 \mathrm{~m}$ over the entire domain and was divided into 5 vertical

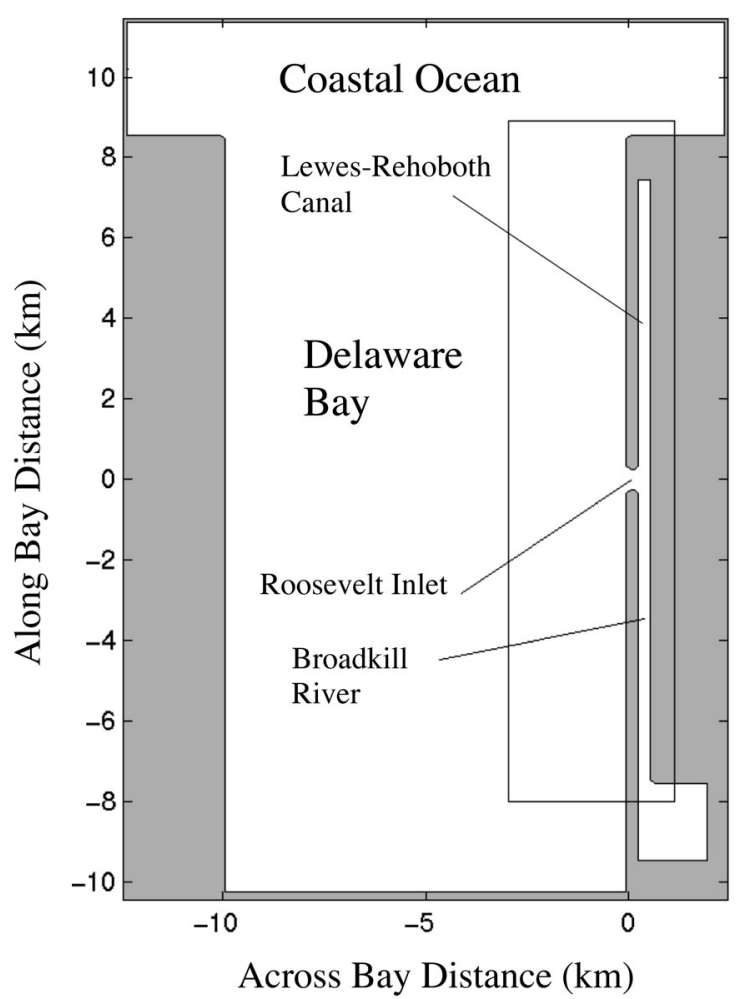

Fig. 3. Numerical model domain. Note the superimposed rectangle that represents the portion of the model shown in Fig. 8

levels. Finite difference time steps were $16 \mathrm{~s}$ for the baroclinic and $3.2 \mathrm{~s}$ for the barotropic components. Halving the time steps or the grid size had no appreciable effect on the simulation.

Patches of zoeae in the coastal ocean. This component of the study consisted of collections of Uca larvae in the coastal ocean. This was part of a larger effort during the summer of 1999 that targeted larvae of the blue crab Callinectes sapidus (Natunewicz \& Epifanio 2001). The overall program consisted of 8 cruises, and the location of individual sampling sites depended on the movement of satellite-tracked drifters released as part of the study. However, sampling was always conducted southeast of Delaware Bay within an area that extended $40 \mathrm{~km}$ south along the ocean coast and $30 \mathrm{~km}$ east of the coast (Region B of Fig. 1). Sampling during each cruise consisted of a continuous series of $300 \mathrm{~m}$ surface tows along a $3.6 \mathrm{~km}$ transect centered on one of the drifters. Methods for analysis of plankton samples and identification of larvae were similar to those described above. Quantitative spatial characterization of the larval density field was not attempted because the number of samples $(n=11)$ along the respective transects was too small for robust autocorrelation analysis. However, we did conduct Pearson correlation analysis of the relationships among the densities of the respective zoeal stages along each of the transects. 

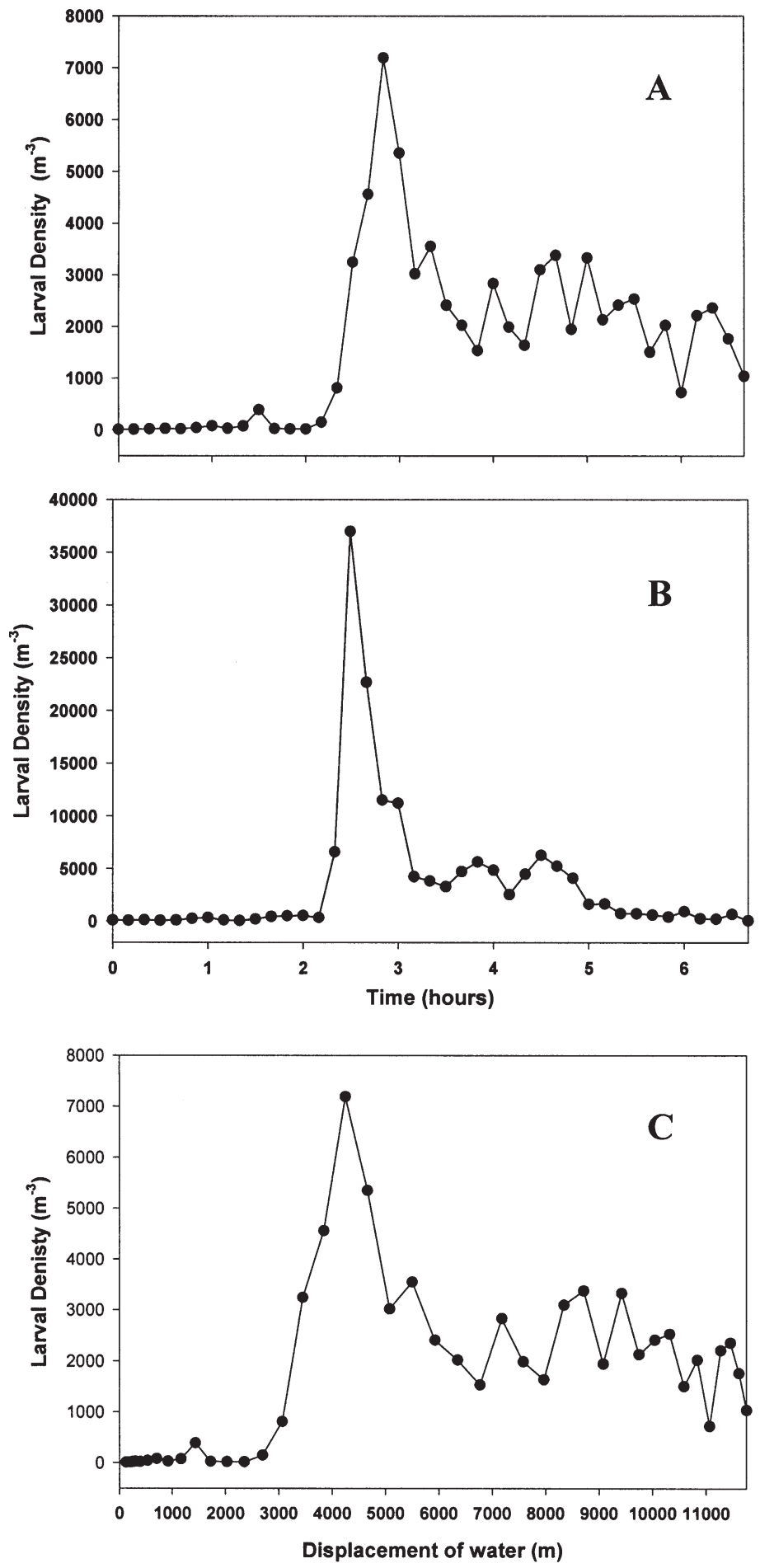

Fig. 4. Distribution of stage I Uca zoeae at a sampling station $500 \mathrm{~m}$ upstream from the mouth of the Broadkill River (see Fig. 1) following a hatching event in adjacent marshes. (a) Original time series of larval density in June 2001. (Samples were collected every $10 \mathrm{~min}$ starting at Time 0.) (b) Original time series of larval density in August 2001. (c) Derived spatial distribution of larvae in June 2001. (Spatial distribution for August 2001 not shown.) Along-stream dimension is distance upstream from the mouth of the river
Patches of megalopae in Delaware Bay and the Broadkill River. The final part of the investigation concerned the distribution of $U_{c a}$ megalopae as they were transported to juvenile habitat in marshes fringing Delaware Bay. A single patch of megalopae was encountered in August 2002 as part of the program of sampling for zoeae in Delaware Bay. In addition, we undertook dedicated sampling of megalopae in the Broadkill River on 3 nights in August 1999. This sampling period occurred during a strong downwelling event when transport of megalopae into the river was expected to be maximum (Little \& Epifanio 1991, Jones \& Epifanio 1995). Methods for sampling and subsequent analysis of data were similar to those described above for zoeae in the Broadkill. Each sampling period consisted of $2 \mathrm{~min}$ plankton collections taken every 6 min over several hours during the nocturnal flood phase of the tide. Resulting time series of megalopal density were converted to spatial series (see above), which were plotted for visual inspection. Because the downwelling event caused extensive flooding at the collection site, we were unable to collect samples throughout the entire flood phase, and the total duration of sampling each night varied in concert with the degree of flooding. Thus, the data series were not long enough to support formal analysis of patch dimensions.

\section{RESULTS}

\section{Genesis of patches}

Patterns of abundance of Z-I at the Broadkill site were similar during the 2 sampling periods in 2001 (Fig. 4a,b). Larval densities were low during the first $2 \mathrm{~h}$ of ebbing tide, but increased sharply thereafter. Peak abundance occurred at approximately the same point in the ebb-tide phase on both sampling dates. Sampling in June 2001 was conducted early in the UCa spawning season, but maximum densities of Z-I larvae still reached nearly $7 \times 10^{3} \mathrm{~m}^{-3}$. August sampling at the height of the spawning season yielded truly remarkable densities of Z-I larvae with maximum values $>3.2 \times 10^{4} \mathrm{~m}^{-3}$. Spatial distribution of larvae in the river on both nights of sampling showed the continuous transport of newly hatched larvae past the sampling site during the last $4 \mathrm{~h}$ of the ebbing tide (Fig. 4c).

\section{Patch dynamics in Delaware Bay}

All of the Delaware Bay sampling was conducted in area A as shown in Fig. 1. In 2001, we were successful in tagging 4 patches of Z-I as they were transported out of the Broadkill and into open water. Maps of larval 

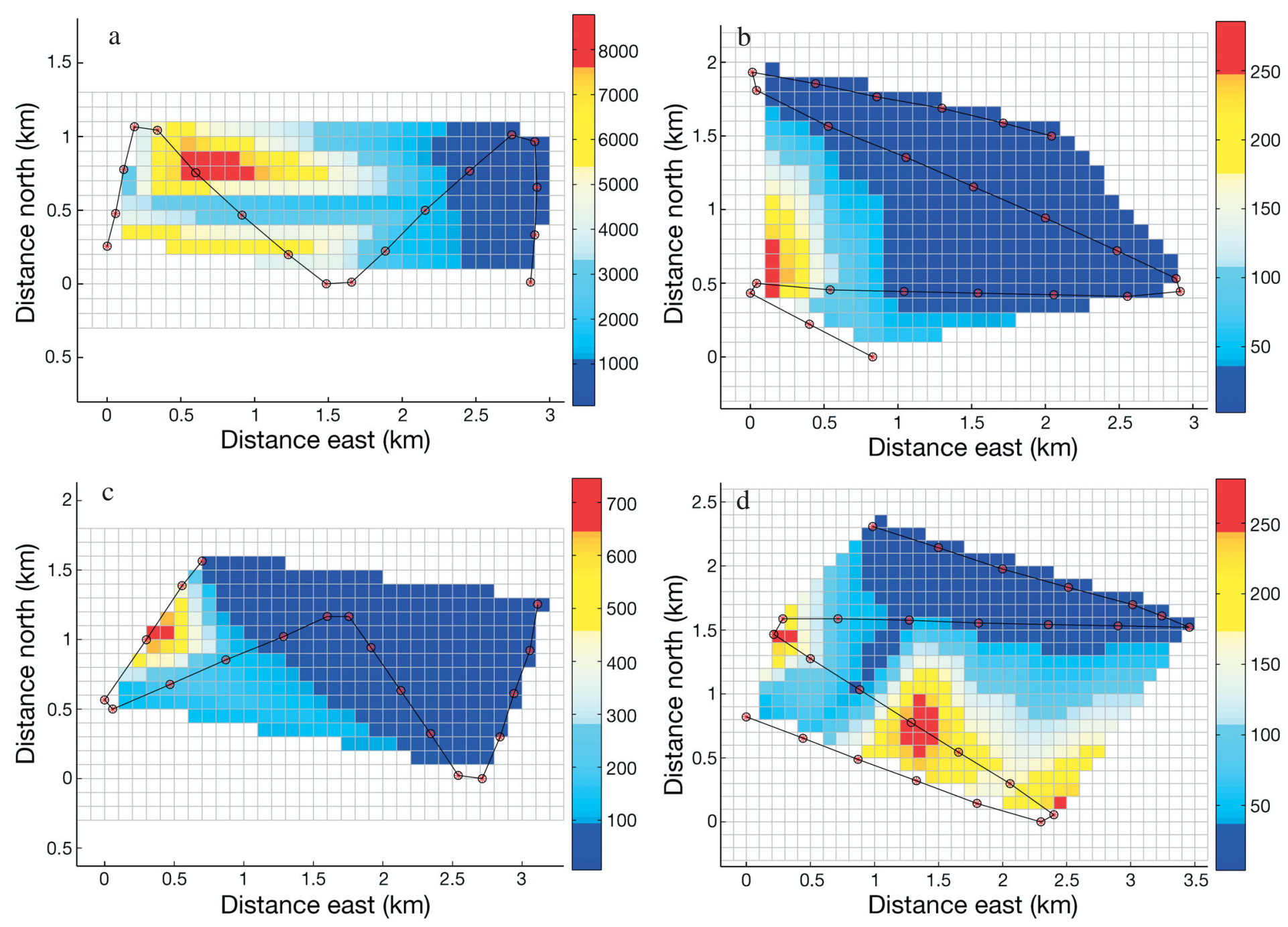

Fig. 5. Distribution of stage I Uca zoeae in 4 patches tagged with satellite-tracked drifters in Delaware Bay near the mouth of the Broadkill River (area A in Fig. 1). Maps show spatial distribution of zoeae $6 \mathrm{~h}$ after a spawning event in adjacent marshes. Units on color bar are larvae $\mathrm{m}^{-3}$. $Y$-axis extends northward; $X$-axis extends eastward. Dark line shows W-shape of transect; points delineate sampling intervals (see Fig. 2). Interpolation was restricted to the area encompassed by the transects. Analysis did not extend to the open squares external to the transects. (a) August 20, 2001. (b) August 21, 2001. (c) September 3, 2001.

(d) September 4, 2001

density show that patches spread out after leaving the lateral constraints of the river (Fig. 5). However, our sampling regime was unsuccessful in resolving the complete 2-dimensional structure of any of the patches. Maximum densities of Z-I larvae in bay patches varied from $~ 800$ to $9500 \mathrm{~m}^{-3}$. Densities outside of the patches, but still within the sampling grids, were typically $<1 \times 10 \mathrm{~m}^{-3}$.

During the summer of 2002, we were successful in tracking 2 patches of Z-I for periods beyond $6 \mathrm{~h}$. The first patch (July 23) was initially sampled $6 \mathrm{~h}$ after deployment of the drifter ( $=12 \mathrm{~h}$ post-hatching) and had a maximum density of $\sim 2500$ zoeae $\mathrm{m}^{-3}$. The patch was located on the eastern edge of the sampling grid and little of its structure was resolved (Fig. 6a). The area around the drifter was sampled again at $18 \mathrm{~h}$ posthatching. Maximum density was $\sim 1400$ zoeae $\mathrm{m}^{-3}$, and the patch was again restricted to the eastern edge of the grid, although more of its structure was resolved (Fig. 6b). Subsequent sampling was abandoned due to strong winds and rough seas.

The second patch (August 9) was initially sampled $30 \mathrm{~h}$ after deployment of the drifter $(=36 \mathrm{~h}$ posthatching). The long delay resulted from attempts to solve problems associated with another drifter that had been deployed on the same date. The patch extended from the middle of the sampling grid to at least its southern edge, a distance of at least $1 \mathrm{~km}$ (Fig. $7 \mathrm{a}$ ). 
Maximum density was $\sim 1300$ zoeae $\mathrm{m}^{-3}$. The patch was sampled again at $48 \mathrm{~h}$ post-hatching. Maximum density was similar ( 2000 zoeae $\left.\mathrm{m}^{-3}\right)$ and again the patch extended a similar dimension $(\sim 1 \mathrm{~km})$ from the center of the grid to at least the southern border of the grid (Fig. 7b).

Trajectories of the observed patches were driven by flow at tidal frequency, which was expected, given the short duration of each cruise. Patches of Uca larvae remained close to shore and were transported back and forth along the coast at tidal frequency (Fig. 8).

\section{Numerical simulation of patch genesis}

Examination of the numerical simulation revealed good agreement with the observations of larval densities and patch generation. Fig. 9 shows the time of evolution of a tracer that simulates the UCa larvae over 2.25 tidal periods. At time $=0$, the larvae (tracer) were introduced into the upper meter of the Broadkill River as a $7 \mathrm{~km}$ slug extending upstream from the mouth of the river. The initial normalized concentration of the larvae was set at 1.0. The simulation was
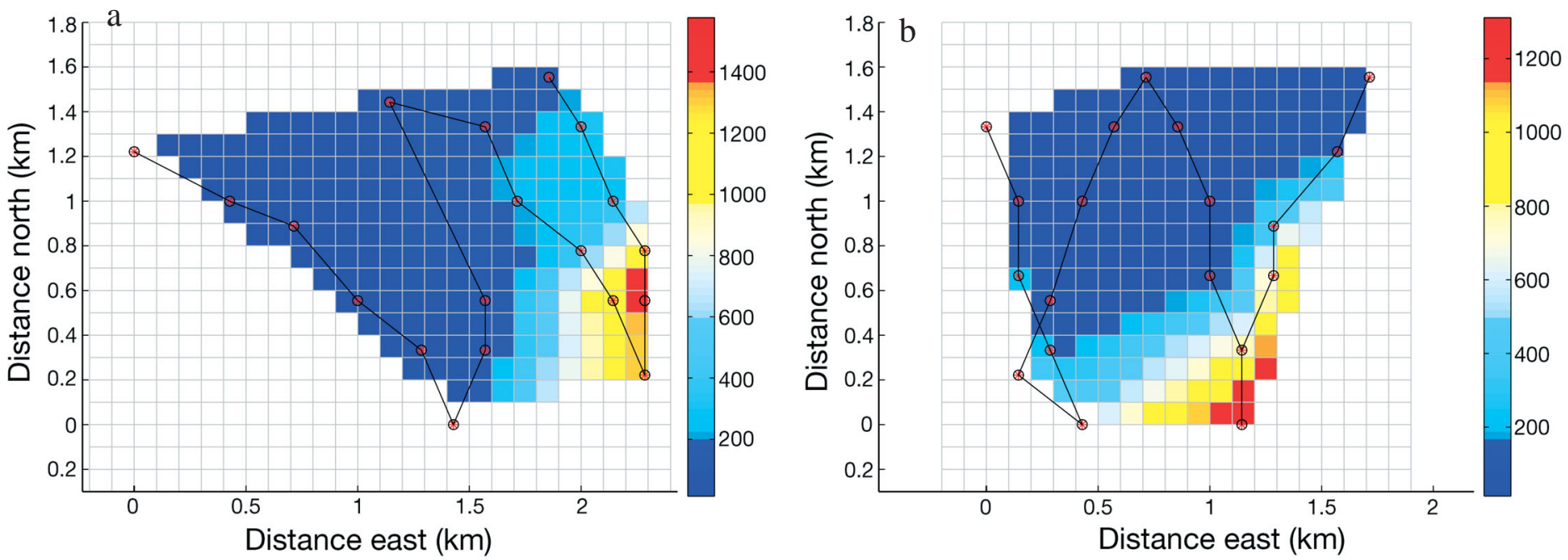

Fig. 6. Distribution of Stage I Uca zoeae in 2 patches tagged with satellite-tracked drifters in Delaware Bay (July 23, 2002). Maps show spatial distribution of zoeae $12 \mathrm{~h}$ (a) and $18 \mathrm{~h}$ (b) after a spawning event in adjacent marshes. Units on color bar are larvae $\mathrm{m}^{-3}$. (See Fig. 5 for additional details)
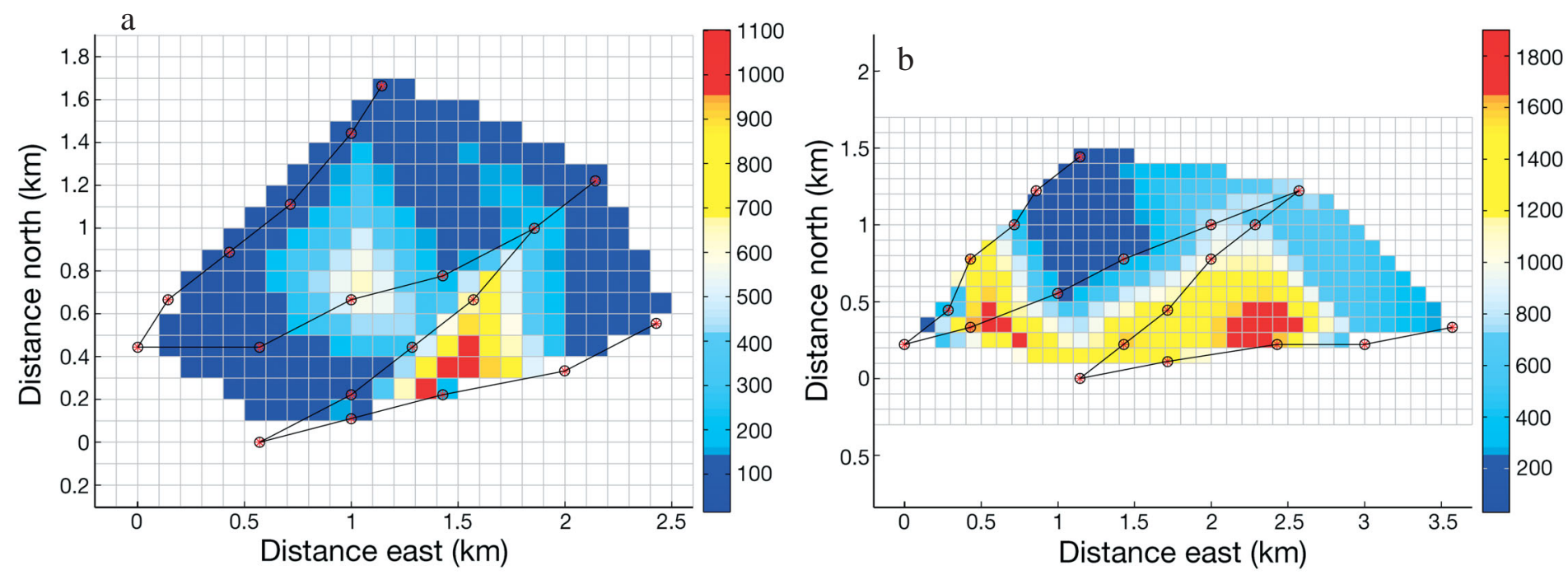

Fig. 7. Distribution of Stage I Uca zoeae in 2 patches tagged with satellite-tracked drifters in Delaware Bay (August 9, 2002). Maps show spatial distribution of zoeae $36 \mathrm{~h}$ (a) and $48 \mathrm{~h}$ (b) after a spawning event in adjacent marshes. Units on color bar are larvae $\mathrm{m}^{-3}$. (See Fig. 5 for additional details) 


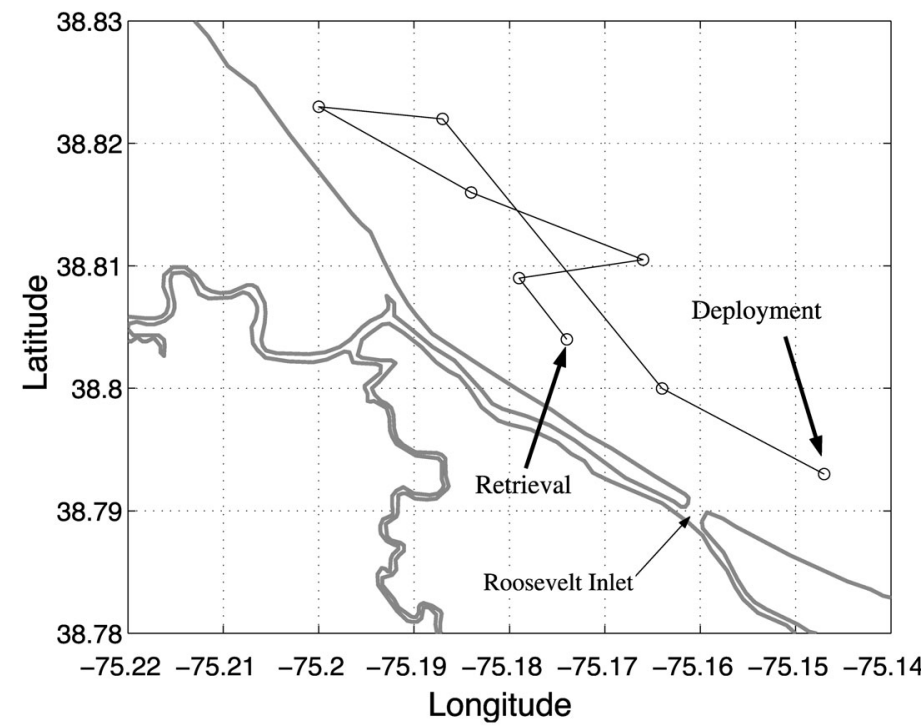

Fig. 8. Satellite-derived drifter trajectory showing initial upbay movement of a drifter-tagged patch of Stage I Uca zoeae during flood tides and down-bay movement during ebb tides. Drifter was deployed $6 \mathrm{~h}$ after a spawning event in adjacent marshes. Duration of tracking was approximately $21 \mathrm{~h}$. August 2002 then allowed to progress over several tidal periods During the first ebb tide (time $=0.25$ tidal periods) the larvae began to exit the river and enter the bay as a relatively thin plume. At low slack-tide (time $=0.5$ tidal periods), the larvae had been advected nearly $6 \mathrm{~km}$ from the mouth of the river. However, this distance was not sufficient for the tail of the tracer slug to exit the river. During the first flood tide (time = 0.75 tidal periods), the majority of the larvae returned to the river, however, a small portion (with a horizontal scale of $\sim 0.5 \mathrm{~km}$ ) remained within the bay. The normalized concentration within the patch had decreased to 0.5 . During the following ebb tide (time $=1.25$ to 1.5 tidal periods), the larvae again left the river; however, the larvae were no longer confined to as thin a plume due to mixing. During the second flood tide (time $=1.75$ tidal periods), additional larvae joined the previous patch, increasing its size to horizontal scales of $\sim 1 \mathrm{~km}$. Additional mixing had reduced the larval concentrations to $\sim 0.2$. Examination of the patch over 5 more tidal periods (not shown) revealed that the spatial scale of the patch increased slightly, but the patch remained near to the
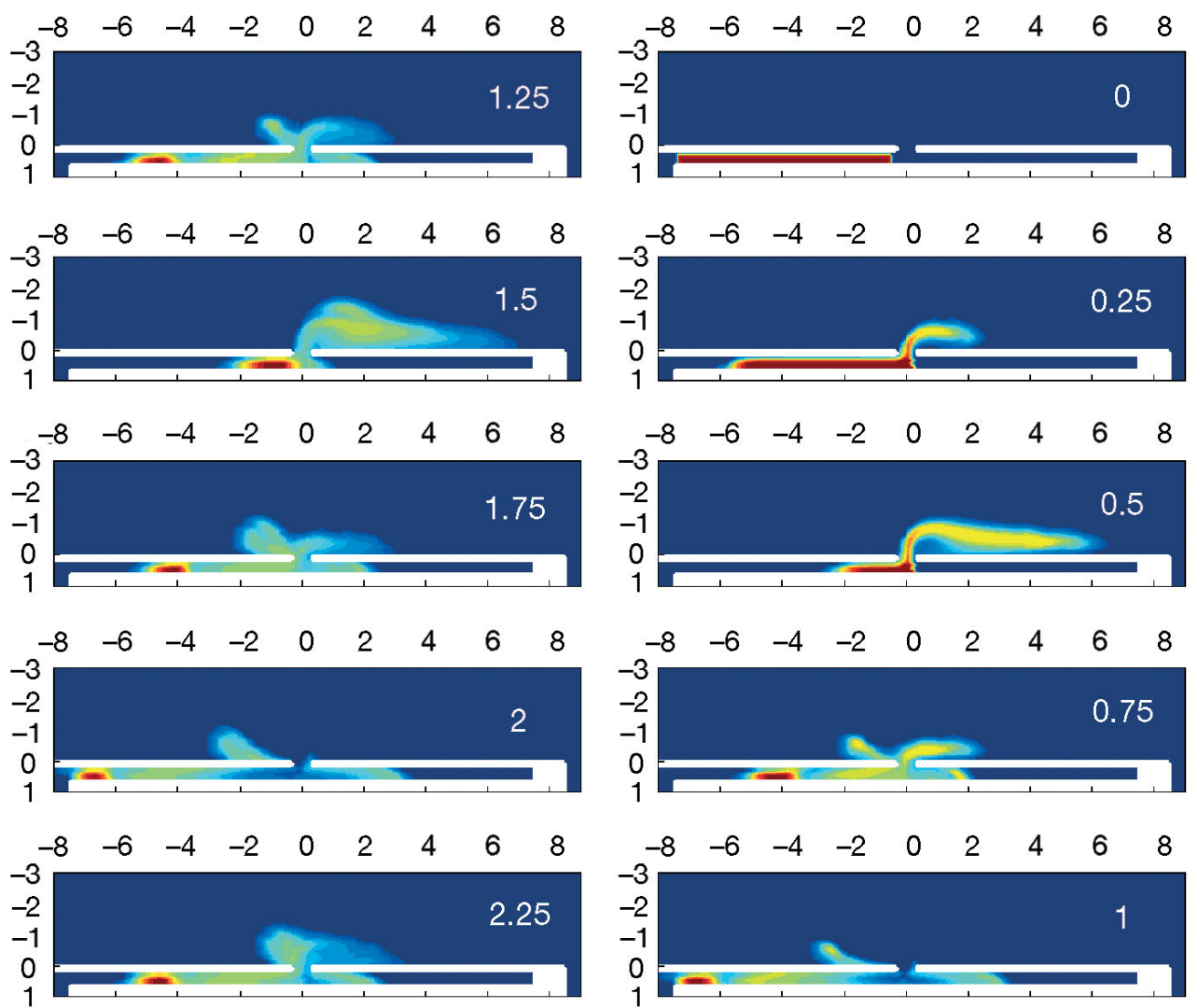

Fig. 9. Normalized concentration of tracer over 2.25 tidal periods (cycles). White numbers represent respective tidal periods. Zero value in upper right panel designates a hatching event at initial high slack water; 0.5 value in third right panel designates first low slack water; etc. Numbers on axes represent distance in $\mathrm{km}$. The white box at the bottom of each panel shows locations of Broadkill River (left), Roosevelt Inlet (center), and canal (right). Dark blue area above the box is Delaware Bay. Red color indicates maximum tracer concentrations. Light blue color indicates minimum concentrations 


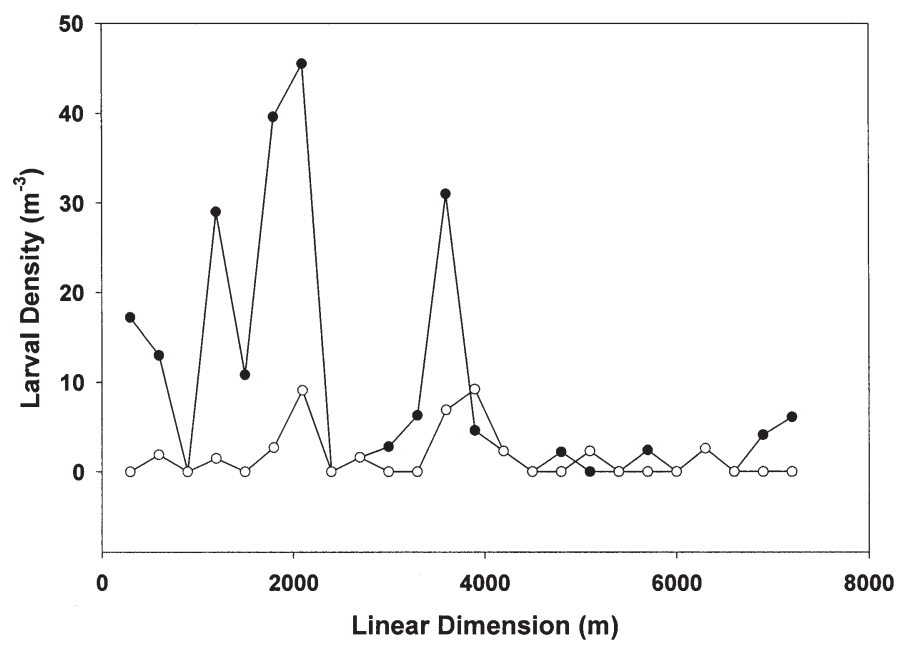

Fig. 10. Density of $U_{c a}$ larvae along a transect in the coastal ocean near the mouth of Delaware Bay $\left(\sim 38.6^{\circ} \mathrm{N}, 74.9^{\circ} \mathrm{W}\right.$; see Fig. 1). Sampling interval is $300 \mathrm{~m}$. (০) zoea Stage I. (•) zoea Stage I. Note spatial correspondence between peaks of respective stages. August 1999

shore and traveled up and down the shore at a semidiurnal frequency.

The behavior of the tracer within the simulation agreed quite well with the observed larvae, both in initial patch formation and subsequent advection of the patch. As in the observations, the simulated larvae did not entirely exit the river during one tidal period. The spatial scales of both the simulated and observed larval patches were $\sim 1$ to $1.5 \mathrm{~km}$. Analysis shows that trajectories of both simulated and observed patches after formation also agree. The combination of tidal mixing, turbulent diffusion, the retention of larvae in the river (even after 2 tidal cycles), and dilution due to the efflux of water from the Lewes-Rehoboth Canal was responsible for the dramatic decrease in larval densities observed within patches found in the bay after spawning.

\section{Patches in the coastal ocean}

Patches of UCa larvae were encountered in the coastal ocean during 2 cruises in the summer of 1999. General location of the sampling transects is shown as area B in Fig. 1. Explicit location of each patch is defined in the captions of the corresponding figures. In contrast to patches observed in Delaware Bay, coastal ocean patches always contained substantial numbers of advanced zoeal stages. Patches shown in Fig. 10 are composed primarily of Z-I larvae, but with a considerable proportion of Z-II. Results of Pearson correlation analysis showed a relatively high correlation between densities of Z-I and Z-II along the transect $(r=0.57$, $p=0.001)$. Likewise, the patches in Fig. 11 contain larvae that are mostly in Z-III and Z-IV, with a smaller number in Z-V. Correlation among the densities of the respective stages along this transect was also high: Z-III vs. Z-IV ( $r=0.95, p<0.001)$; Z-III vs. Z-V ( $r=0.59$, $\mathrm{p}=0.059)$; and Z-IV vs. $\mathrm{Z}-\mathrm{V}(\mathrm{r}=0.74, \mathrm{p}=0.009)$. Small numbers of Z-I and Z-II also occurred in this patch, but are not shown in the figure.

\section{Patches of Megalopae in Delaware Bay and the Broadkill River}

A single patch of $U_{c a}$ megalopae was encountered in Delaware Bay in August 2002 (Fig. 12). General location of the patch is shown as area A in Fig. 1; explicit location is defined in the caption for Fig. 12. The patch was restricted to the northwest corner of the sampling grid. Maximum density was $\sim 80 \mathrm{~m}^{-3}$. Patches of megalopae were also observed in the Broadkill River on all 3 nights of sampling in August 1999 (Fig. 13). Maximum density on the respective nights ranged from around 500 to $600 \mathrm{~m}^{-3}$.

\section{DISCUSSION}

\section{Analysis of field observations}

Results of this investigation indicate that newly hatched fiddler crab larvae are exported from small tidal rivers like the Broadkill in a long continuous stream lasting through the ebb tide phase. The length of this patch would vary if measured at different points along the river. However, the volume occupied by the

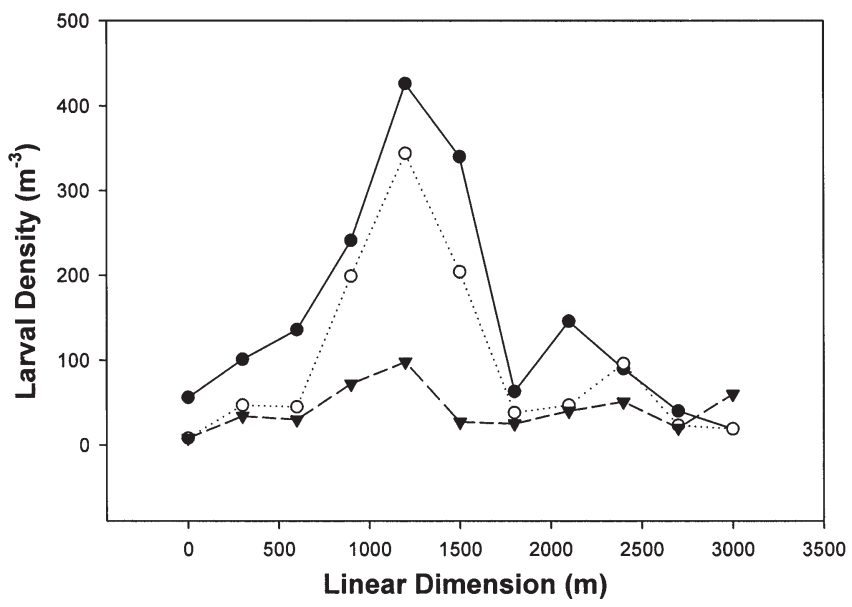

Fig. 11. Density of $U_{C a}$ larvae along a transect in coastal ocean near mouth of Delaware Bay $\left(\sim 38.8^{\circ} \mathrm{N}, 74.7^{\circ} \mathrm{W}\right.$; see Fig. 1). Sampling interval is $300 \mathrm{~m}$. (•) zoea Stage III, (০) zoea Stage IV, ( $\mathbf{\nabla})$ zoea Stage V. Note spatial correspondence between peaks of respective stages. August 1999 


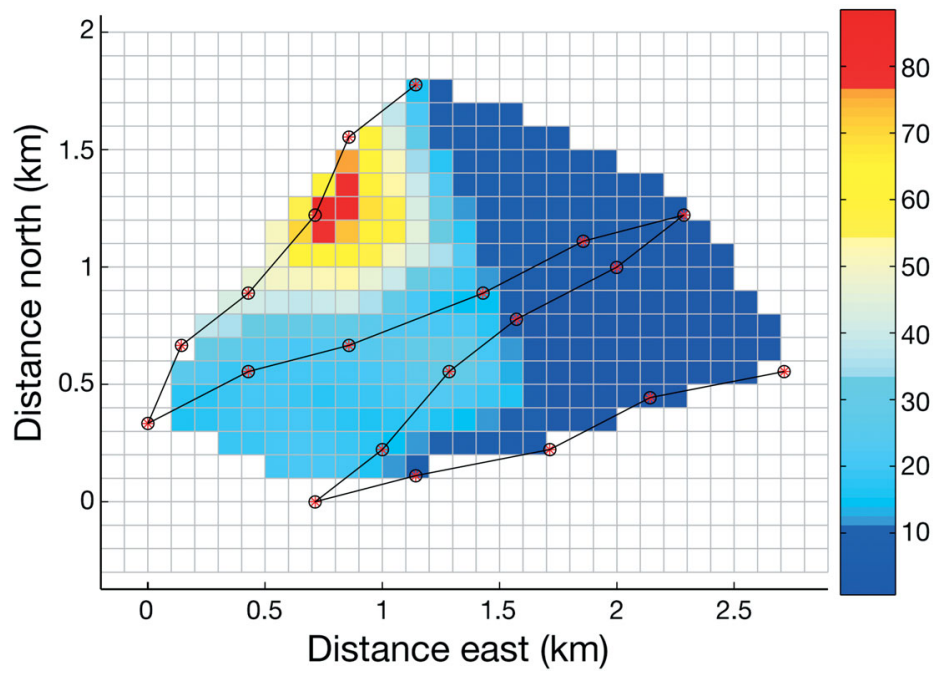

Fig. 12. Distribution of Uca megalopae in a patch in Delaware Bay near the mouth of the Broadkill River (August 9, 2002). Units on color bar are megalopae $\mathrm{m}^{-3}$. (See Fig. 5 for additional details)

larvae would not change on short (tidal) time scales, as little diffusion could occur. We estimated the alongchannel length scale as 8-9 $\mathrm{km}$ for our station near the mouth of the river. Because the cross-sectional area of the channel was minimal at this location, the current and the corresponding patch length scale were greatest at this point. There is no single patch length that is applicable to the history of the larval outflow. Instead, we estimated the length scale appropriate to the circumstances.

On both nights of river sampling, the density of $U_{C a}$ larvae was essentially zero for the first $2 \mathrm{~h}$ of ebbing tide, after which there was a sudden spike in abundance. This may have been related to the time required to transport larvae from spawning sites in the marsh to our sampling station near the mouth of the river. The occurrence of high densities within a few hours of the expected hatching time (high slack water) implies that genesis of patches in this species is the result of synchronized hatching by aggregations of large numbers of females in marshes located along the length of the river. Model simulations showed a similar pattern in the temporal occurrence of larvae near the mouth of the river (see below). The observed larval concentrations remained relatively high throughout the period of ebb current and did not return to zero at the end of the ebb phase. This indicated that the initial patch of larvae had not entirely left the river during the first ebb tide after hatching. This conclusion was also supported by subsequent modeling studies.

Simple scale analysis reveals that the failure of an entire patch to exit the Broadkill River during a single ebb tide phase is expected. Since the M2 tide domi- nates flow within Delaware Bay and the Broadkill River, and because the maximum observed velocity within the river was $\sim 80 \mathrm{~cm} \mathrm{~s}^{-1}$, the observed tidal velocities within the river can be approximated as

$$
U(t)=80 \sin \left(\frac{2 \pi}{T} t\right) \quad\left(\mathrm{cm} \mathrm{s}^{-1}\right)
$$

where $t$ is time and $T$ is the semi-diurnal tidal period $(12.42 \mathrm{~h})$. So, the distance, $X$, traveled by the tail of the river patch can be determined by integrating this velocity over $1 / 2$ tidal period $(6.21 \mathrm{~h})$ :

$$
X=\int_{0}^{\frac{1}{2} T} U(t) \mathrm{d} t=\int_{0}^{\frac{1}{2} T} 80 \sin \left(\frac{2 \pi}{T} t\right) \mathrm{d} t=5.7 \times 10^{5} \mathrm{~cm}=5.7 \mathrm{~km}
$$

which would not result in the entire patch (whose length is $\sim 8$ to $9 \mathrm{~km}$ ) leaving the river.

Upon reaching open waters of Delaware Bay, the river patches spread out as a result of physical processes associated with tidal flow out of the river. We were unsuccessful in resolving the entire structure of these patches, but the part that was resolved typically had a length scale on the order of $1 \mathrm{~km}$. Trajectories of bay patches were strongly influenced by tidal circulation, which resulted in the transport of larvae back and forth along the shore of the bay at tidal frequency. The duration of satellite tracking was insufficient to resolve
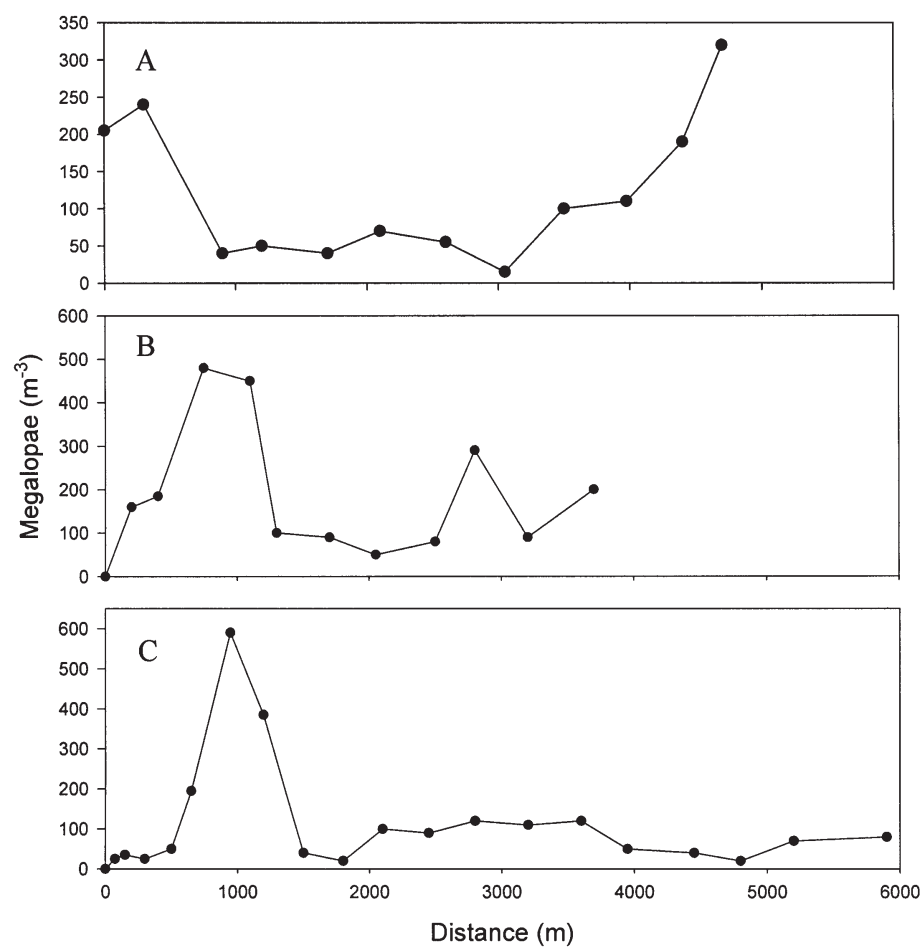

Fig. 13. Spatial distribution of $U_{C a}$ megalopae in the Broadkill River near the mouth of Delaware Bay. Values on $x$-axis are displacement of water (m) past sampling station. (a) August 31, 1999, (b) September 1, 1999, and (c) September 2, 1999 
the subtidal motion of these patches, but the buoyancy-driven, seaward flow that is characteristic of subtidal surface circulation in southern Delaware Bay would eventually result in the export of these larvae to the adjacent coastal ocean (Epifanio \& Garvine 2001).

We were successful in tracking patches in Delaware Bay for periods up to $48 \mathrm{~h}$ post-hatching. This is similar to results from earlier work with blue crab larvae wherein investigators were able to infer the persistence of patches for up to $6 \mathrm{~d}$ from hatching (Natunewicz et al. 2001). In both investigations, the density of larvae within the patches decreased during the tracking period, presumably due to effects of turbulent diffusion (Natunewicz \& Epifanio 2001) and predation (Morgan \& Christy 1996).

Support for the idea that patch structure is maintained beyond the period established by our drifter studies comes from the investigation of the spatial distribution of Uca larvae collected in the coastal ocean adjacent to Delaware Bay. While the number of data points along these transects was insufficient to support autocorrelation analysis, visual inspection of the data showed a patchy distribution of larvae. Moreover, these aggregations contained high densities of larvae in advanced zoeal stages. For example, one patch sampled in the coastal ocean during peak spawning season in August had maximum densities of $\sim 400 \mathrm{~m}^{-3}$ for Z-III larvae, $350 \mathrm{~m}^{-3}$ for Z-IV, and $100 \mathrm{~m}^{-3}$ for Z-V (Fig. 11). In addition, there was moderate to high correlation among the densities of the respective stages along the transect, i.e. the spatial distribution of the respective stages varied in phase. This supports the idea that the high densities of all 3 stages occurred within a single patch. Variation in development rates among different broods of larvae constituting the patch probably accounts for the coincident occurrence of larvae in Stages Z-III, Z-IV, and Z-V (Epifanio et al. 1994, Welch \& Epifanio 1995).

Sampling in Delaware Bay and the Broadkill River also indicated that fiddler crab megalopae may be distributed in discrete patches. However, the well established tidal-diel pattern of vertical migration of $U_{C a}$ megalopae within an estuary (Tankersley \& Forward 1994) may also influence the spatial distribution of megalopae in the horizontal dimension (Jones \& Epifanio 2004). Thus, caution is required in interpreting the observed patchy distribution. That aside, we were unsuccessful in resolving the entire 2-dimensional structure of bay patches, but maximum density was 1 to 2 orders of magnitude lower than for Z-I patches. Densities of megalopae in the river samples were typically higher, reaching levels of $\sim 600 \mathrm{~m}^{-3}$. The generality of this difference is not discernable from the small numbers of megalopal patches observed in this investigation.

\section{Analysis of model simulations}

Examination of the numerical simulations reveals that the phase difference between tidal velocities within the Broadkill River and Delaware Bay results in convergence of the surface flow near the river inlet and retention of larvae within the bay. Observations within the bay and the river show that tidal velocities within the river lag those in the bay by approximately 1 to $2 \mathrm{~h}$ (DeWitt \& Daiber 1973); these agree quite well with the numerical model. This phase difference also combines with horizontal mixing in the bay to change the shape of the larval patches. Analysis of the simulation shows that initially the larval concentrations within the patch were relatively high and the spatial scale $(\sim 0.5 \mathrm{~km})$ was significantly less than that observed in the field. However, once the patch was no longer constrained by stream banks and could expand in response to tidal mixing and turbulent diffusion, the spatial scales of the patch increased. The combination of additional larval patches from subsequent ebb tides and this mixing resulted in quasi-circular patches with spatial scales that agreed quite well with observations ( 1 to $1.5 \mathrm{~km})$ and larval concentrations that were approximately an order of magnitude less than those found in the Broadkill River.

\section{CONCLUSION}

Our study has employed a variety of techniques to investigate the dynamics of patches of fiddler crab larvae, starting with their genesis in coastal marshes, continuing through their transport to the coastal ocean, and culminating with the transport of megalopae back to the marshes. This showed a single aggregation of larvae exiting the river each night during the ebb tide following hatching. While the density of larvae varied considerably over the spatial domain of the aggregation, it never approached zero, and we concluded that we were observing a single patch of larvae. We propose that physical processes in the open waters of Delaware Bay would act to change the shape of this patch once it escaped the lateral confines of the river. A numerical simulation of patch genesis (whose domain incorporates the Broadkill River and Delaware Bay) supported this idea. Intensive plankton sampling along transects in Delaware Bay confirmed the occurrence of patches of Z-I at locations predicted by the trajectories of drifters deployed in the mouth of the river during nocturnal, spring, and ebb tides. Subsequent tagging of the patches with satellite-tracked drifters confirmed that they remained integral for at least a few 
days post-hatching while they were still inside the bay. Sampling of additional transects in the coastal ocean again confirmed the existence of patches of fiddler crab larvae, but these differed from bay patches in that the larvae comprising the patches were typically advanced zoeal stages. Finally, highfrequency sampling during flooding tides in the river confirmed the patchy distribution of megalopae as they were transported to nursery habitat in the marshes.

Our overall results provide evidence that fiddler crab larvae are typically distributed in patches. While we were unsuccessful in characterizing the entire 2-dimensional structure of patches in open water, linear dimensions of these patches appear to be on the order of $10^{3} \mathrm{~m}$. This is similar to patch scales reported for crab larvae in earlier studies (Natunewicz \& Epifanio 2001, Jones \& Epifanio 2004). Maximum density of larvae within Uca patches in the present investigation ranges from tens of thousands $\mathrm{m}^{-3}$ for newly hatched zoea to several hundreds $\mathrm{m}^{-3}$ for advanced zoea stages and megalopae. In all cases, the density of larvae within patches was much greater than reported in more general surveys of larval distribution (e.g. Dittel \& Epifanio 1982, Brookins \& Epifanio 1985 ) and much greater than observed in regions outside of the patches within our own sampling grids. On time scales of a few days, the trajectories of these patches correspond well to flow at semi-diurnal tidal frequency, and on longer time scales we would expect trajectories to respond to subtidal processes such as buoyancy and wind driven circulation (Natunewicz et al. 2001).

Our results make a clear case that patches of earlystage fiddler crab larvae are generated through interaction between the synchronized spawning activity of large aggregations of females and a set of co-occurring physical processes. Moreover, we have demonstrated that advanced zoea larvae and megalopae may be distributed in similar patches within the estuary or the contiguous coastal ocean. What is not clear is whether individual patches typically remain integral throughout the entire course of larval development or whether they are repetitively dispersed and re-aggregated by physical processes.

Acknowledgements. This research was supported by funds from the University of Delaware Sea Grant College Program and from the National Science Foundation (OCE-9876866). The authors thank E. Grey, L. Houser, S. Park, and C. Tallamy for assistance with field collections. We are especially grateful to our colleague R. W. Garvine for help with 2-dimensional representation of larval densities and for discussion of circulation in the study area. Comments from the contributing editor (L. Levin, Scripps Institution of Oceanography) and from 2 anonymous reviewers improved the manuscript considerably.

\section{LITERATURE CITED}

Ashjian CJ, Smith SL, Flagg CN, Mariano AJ, Behrens WJ, Lane PV (1994) The influence of a Gulf Stream meander on the distribution of zooplankton biomass in the slope water, the Gulf Stream, and the Sargasso Sea, described using a shipboard acoustic Doppler current profiler. DeepSea Res 41:23-50

Blumberg AF, Mellor GL (1987) A description of a threedimensional coastal ocean circulation model. In: Heaps NS (ed) Three-dimensional coastal ocean models. American Geophysical Union, Washington, DC, p 1-16

Brookins KG, Epifanio CE (1985) Abundance of brachyuran larvae in a small coastal inlet over six consecutive tidal cycles. Estuaries 8:60-67

Christy JH (1982) Adaptive significance of semilunar cycles of larval release in fiddler crabs (genus Uca): test of an hypothesis. Biol Bull 163:251-263

Christy JH, Morgan G (1998) Estuarine immigration by crab postlarvae: mechanisms, reliability and adaptive significance. Mar Ecol Prog Ser 174:51-65

DeWitt P, Daiber FC (1973) The hydrography of the Broadkill River Estuary, Delaware. Ches Sci 14:28-40

Dittel AI, Epifanio CE (1982) Seasonal abundance and vertical distribution of crab larvae in Delaware Bay. Estuaries 5:197-202

Epifanio CE (1995) Transport of blue crab (Callinectes sapidus) larvae in the waters off mid-Atlantic states. Bull Mar Sci 57:713-725

Epifanio CE (1988) Transport of invertebrate larvae between estuaries and the continental shelf. Trans Am Fish Soc Symp Ser 3:104-114

Epifanio CE, Garvine RW (2001) Larval transport on the Atlantic continental shelf of North America: a review. Estuar Coast Shelf Sci 52:51-77

Epifanio CE, Little K, Rowe PM (1988) Dispersal and recruitment of fiddler crab larvae in the Delaware River estuary. Mar Ecol Prog Ser 43:181-188

Epifanio CE, Lobanoff M, Connaughton VP, Welch J (1994) Growth and development of mud crab larvae in fielddeployed enclosures and in the laboratory. J Exp Mar Biol Ecol 180:165-174

Fortier L, Leggett WC (1984) A drift study of larval fish survival. Mar Ecol Prog Ser 25:245-257

Franks PJS (1997) Spatial patterns in dense algal blooms. Limnol Oceanogr 42:1297-1305

Garvine RW (1991) Subtidal frequency estuary-shelf interaction: observations near Delaware Bay. J Geophys Res 96:7049-7064

Jones MB, Epifanio CE (1995) Settlement of brachyuran megalopae in Delaware Bay: a time series analysis. Mar Ecol Prog Ser 125:67-76

Jones MB, Epifanio CE (2005) Patches of crab megalopae in the mouth of Delaware Bay: an analysis of spatial scales. J Shellfish Res 24:261-267

Kourafalou VH, Oey LY, Wang JD, Lee TN (1996) The fate of river discharge on the continental shelf. 1. Modeling the river plume and the inner shelf coastal current. J Geophys Res (C Oceans) 101:3415-3434

Lamare MD, Stewart BG (1998) Mass spawning by the sea urchin Evechinus chloroticus (Echinodermata: Echinoidea) in a New Zealand fiord. Mar Biol 132: 135-140

Lambert R, Epifanio CE (1982) A comparison of dispersal strategies in two genera of brachyuran crab in a secondary estuary. Estuaries 5:182-188

Little KT, Epifanio CE (1991) Mechanism for the re-invasion 
of the estuary by two species of brachyuran megalopae. Mar Ecol Prog Ser 68:235-242

MacKenzie BR (2000) Turbulence, larval fish ecology, and fisheries recruitment: a review of field studies. Oceanol Acta 23:357-375

Morgan SG, Christy JH (1996) Survival of marine larvae under the countervailing selective pressures of photodamage and predation. Limnol Oceanogr 41:498-504

Münchow A, Garvine RW (1993) Buoyancy and wind forcing of a coastal current. J Mar Res 51:293-322

Natunewicz CC (2000) Patchiness of crab larvae in coastal waters: a multi-scale analysis. PhD dissertation, University of Delaware, Newark, DE

Natunewicz CC, Epifanio CE (2001) Spatial and temporal scales of zoeal patches in coastal waters. Mar Ecol Prog Ser 212:217-222

Natunewicz CC, Epifanio CE, Garvine RW (2001) Transport of crab larval patches in the coastal ocean. Mar Ecol Prog Ser 222:143-154

O'Connor NJ (1990) Morphological differentiation and molting of juvenile fiddler crabs (UCa pugilator and U. pugnax). J Crust Biol 10:608-612

Ouellet P, Lefaivre D (1994) Vertical distribution of northern shrimp (Pandalus borealis) larvae in the Gulf of St. Lawrence: implications for trophic interactions and transport. Can J Fish Aquat Sci 51:123-132

Press WHS, Teukolsky SA, Vetterling WT, Flannery BP (1992) Interpolation and extrapolation. In: Press WH, Teukolsky SA, Vetterling WT, Flannery BP (eds) Numerical recipes in

Editorial responsibility: Lisa Levin (Contributing Editor), La Jolla, California, USA
C. The art of scientific computing, (2nd edn). Cambridge University Press, Cambridge, UK, p 114-116

Sandifer PA (1972) Morphology and ecology of Chesapeake Bay decapod crustacean larvae. PhD dissertation, University of Virginia, Charlottesville, VA

Stabeno PJ, Schumacher JD, Bailey KM, Brodeur RD, Cokelet ED (1996) Observed patches of walleye Pollock eggs and larvae in Shelikof Strait, Alaska: their characteristics, formation, and persistence. Fish Oceanogr 5(Suppl 1): $81-91$

Tankersley RA, Forward RBJr (1994) Endogenous swimming rhythms in estuarine crab megalopae: implications for flood-tide transport. Mar Biol 118:415-423

Tankersley RA, Wieber MG, Sigala MA, Kachurak KA (1998) Migratory behavior of ovigerous blue crabs, Callinectes sapidus: evidence for selective tidal-stream transport. Biol Bull 195:168-173

Welch J, Epifanio CE (1995) Effect of variations in prey abundance on growth and development of crab larvae reared in the laboratory and in large, field-deployed enclosures. Mar Ecol Prog Ser 116:55-64

Wheeler D (1978) Semilunar hatching periodicity in the mud crab Uca pugnax (Smith). Estuaries 1:268-269

Williams DM, English S (1992) Distribution of fish larvae around a coral-reef: direct detection of a mesoscale, multispecific patch. Cont Shelf Res 12:923-937

Wong KC, Münchow A (1995) Buoyancy forced interaction between estuary and inner shelf: observation. Cont Shelf Res 15:59-88

Submitted: January 12, 2004; Accepted: October 17, 2004 Proofs received from author(s): May 12, 2005 